\title{
Wide band gap silicon carbon nitride films deposited by electron cyclotron resonance plasma chemical vapor deposition
}

\author{
K.H. Chen ${ }^{\mathrm{a}, *}$, J.-J. Wu ${ }^{\mathrm{a}}$, C.Y. Wen ${ }^{\mathrm{b}}$, L.C. Chen ${ }^{\mathrm{b}}$, C.W. Fan ${ }^{\mathrm{c}}$, P.F. Kuo ${ }^{\mathrm{c}}$, Y.F. Chen ${ }^{\mathrm{c}}$, Y.S. Huang ${ }^{\mathrm{d}}$ \\ ${ }^{a}$ Institute of Atomic and Molecular Sciences, Academia Sinica, Taipei, Taiwan \\ ${ }^{\mathrm{b}}$ Center for Condensed Matter Sciences, National Taiwan University, Taipei, Taiwan \\ ${ }^{\mathrm{c}}$ Department of Physics, National Taiwan University, Taipei, Taiwan \\ ${ }^{\mathrm{d}}$ Department of Electronic Engineering, National Taiwan University of Science and Technology, Taipei, Taiwan
}

\begin{abstract}
We report on the growth of continuous polycrystalline silicon carbon nitride ( $\mathrm{SiCN}$ ) films using electron cyclotron resonance plasma enhanced chemical vapor deposition (ECR CVD). High nucleation density up to $10^{11} \mathrm{~cm}^{-2}$ was demonstrated, which is much higher than other CVD methods. The resultant SiCN films were thus much smoother and continuous, allowing measurement of various properties of the film. RBS studies show that $\mathrm{Si}, \mathrm{C}$, and $\mathrm{N}$ are present in the film and that the nitrogen content in the film could reach as high as $57 \%$. The average grain size estimated from HRTEM images was about $20 \mathrm{~nm}$. For the SiCN film with 4.8 at.\% carbon content, all $d$-spacings of the film observed from TED pattern were similar to those of $\alpha-\mathrm{Si}_{3} \mathrm{~N}_{4}$. High resolution XPS scans showed that the presence of $\mathrm{Si}-\mathrm{C}$ bonds within the film was negligible. From the RBS, XPS and the TEM results, we suggest the silicon carbon nitride film possessed the same structure as $\alpha-\mathrm{Si}_{3} \mathrm{~N}_{4}$ with around 4.8 at. $\% \mathrm{C}$ substituting for $\mathrm{Si}$. It is also demonstrated that this new compound has a direct band gap of about $4.4 \mathrm{eV}$ and an impurity band gap at around $3.0 \mathrm{eV}$. Thus the ternary SiCN compound reported here constitutes an important addition to the wide band gap material with gap energies within the blue spectral region. Furthermore, the nanocrystalline SiCN films deposited by the ECR CVD process were excellent for buffer layers of SiCN film growth. This provides the possibility of growing continuous and even textured SiCN films at a reasonable growth rate, which enables various studies of the films. (C) 1999 Elsevier Science S.A. All rights reserved.
\end{abstract}

Keywords: Silicon carbide nitride; Wide band gap; Chemical vapour deposition

\section{Introduction}

The synthesis of $\mathrm{C}-\mathrm{N}$ compounds has experienced a considerable surge after the prediction by Liu and Cohen [1] of the possibility for realization of $\beta-C_{3} N_{4}$, a covalent $\mathrm{C}-\mathrm{N}$ solid that may be harder than diamond. Despite all kinds of efforts to synthesize $\beta-C_{3} \mathrm{~N}_{4}$ including ion beam deposition, laser ablation of graphite in nitrogen ambient, and reactive sputtering of graphite, the resultant material was mostly amorphous with nitrogen content generally below $40 \%$. Some of the groups have reported the existence of tiny crystallites embedded in the amorphous $\mathrm{C}-\mathrm{N}$ matrix with largest crystallite size smaller than $1 \mu \mathrm{m}$ [2-9]. However, the $d$-values obtained from the TEM diffraction measurements on these crystallites matched only partially with the theoretical values for $\beta-\mathrm{C}_{3} \mathrm{~N}_{4}$. One of the reports of a good match in TED $d$-values is by Hsu et al. [10,11], in

* Corresponding author. Tel.: + 886-02-2366-8232; fax: + 886-022362-0200.

E-mail address: chenkh@po.iams.sinica.edu.tw (K.H. Chen) which an inductively-coupled plasma method was applied for the film deposition.

Stimulated by this previous work and with the successful implementation of microwave plasma enhanced chemical vapor deposition (MW CVD) to grow high quality diamond films, we employed this technique to synthesize $\mathrm{C}-\mathrm{N}$ compound. The formation of well faceted crystals several tens of microns in size has been reported [12-15]. It was observed that silicon incorporation into the films was essential for crystallite formation and that the ternary SiCN compound exhibits superb optoelectronic and mechanical properties. However, the films thus deposited are polycrystalline with low nucleation density, thus leading to restriction on many physical property measurements and applications of the new material.

To improve the quality of the $\mathrm{SiCN}$ films, we have employed the electron cyclotron resonance plasma enhanced chemical vapor deposition (ECR CVD) technique to enhance the nucleation density of the films. Much higher nucleation density, up to $10^{11} \mathrm{~cm}^{-2}$, has been indeed achieved. The films thus grown are smooth and continuous, 


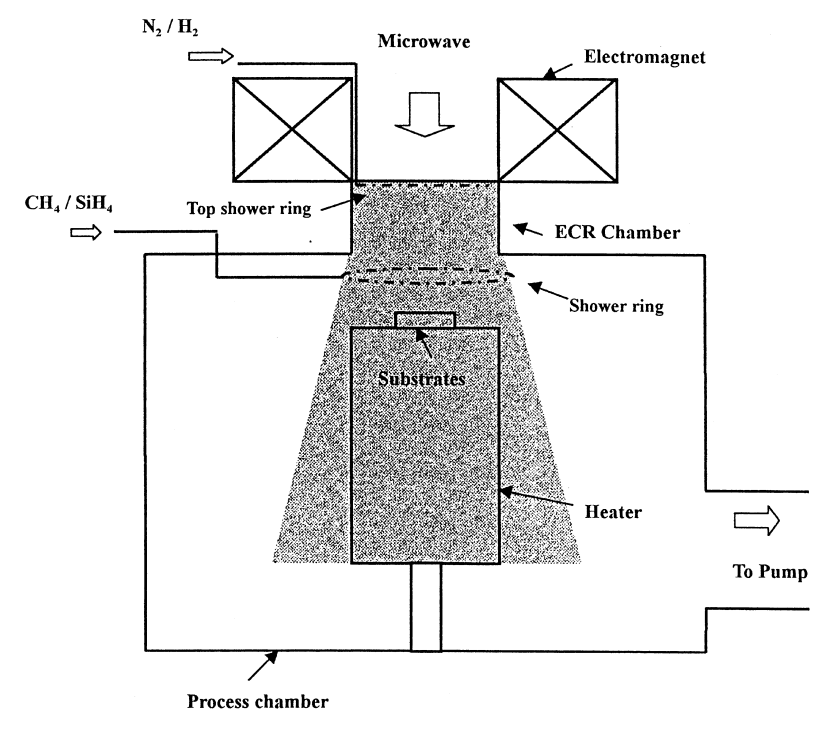

Fig. 1. Schematic diagram of the ECR CVD reactor.

which enables measurements of various physical properties. The chemical composition in these films has been studied by Rutherford backscattering spectroscopy (RBS), while the information on the bonding states of the films is obtained by X-ray photo-electron spectroscopy (XPS). X-ray diffraction (XRD), and transmission electron microscopy (TEM) are used to elucidate the crystal structure. Moreover, the information on the electronic band structure is obtained by piezoreflectance spectroscopy (PzR). Preliminary results on the growth and characterization of the $\mathrm{SiCN}$ films are presented in this paper. A two-step growth method for $\mathrm{SiCN}$ film deposition with reasonable growth rate, larger crystalline size, and high nucleation density is presented as well.

\section{Experimental}

The SiCN films were deposited in an ECR CVD reactor as shown in Fig. 1, which consists of a $40 \mathrm{~cm}$ diameter chamber equipped with a substrate stage in which a $\mathrm{BN}$ heater is used for independent control of the substrate temperature. A $1.5 \mathrm{~kW}$ Astex AX2115 microwave source and an AX4400 electromagnet were employed to generate the ECR plasma as nitrogen or hydrogen was introduced into the reactor from the top shower ring right below the quartz window. The base pressure of the reactor was $1 \times$ $10^{-6}$ Torr evacuated by a turbo molecular pump. The films were deposited on Si (100) and (111) substrates after standard HF acid deoxidization and distilled water cleaning followed by $\mathrm{H}_{2}$ plasma etching of surface impurities. A thermocouple placed underneath the substrate holder was used to monitor the holder temperature. A mixture of semiconductor grade $\mathrm{H}_{2}, \mathrm{CH}_{4}, \mathrm{~N}_{2}$, and $10 \% \mathrm{SiH}_{4}$ diluted in nitrogen was used as the source gas. The typical experimental conditions are presented in Table 1.
The chemical bonding states in the film were determined by X-ray photoelectron spectroscopy (XPS) using a Perkin Elmer Phi 1600 ESCA system. The $\mathrm{Mg} \mathrm{K}_{\alpha}$ radiation of energy $1253.6 \mathrm{eV}$ was used as the source with a linewidth of $0.7 \mathrm{eV}$. The typical analyzer pass energy was $11.75 \mathrm{eV}$ and the analysis area for XPS measurement was $800 \mu \mathrm{m}$ diameter. Depth profiling with XPS was performed by $4 \mathrm{KV} \mathrm{Ar}^{+}$ion beam bombardment of the sample. The RBS measurement for quantitative composition analysis of the films was performed using a ${ }^{4} \mathrm{He}$ energy of $3.5 \mathrm{MeV}$ for increasing the sensitivity of $\mathrm{N}$ and $\mathrm{C}$ elements $[16,17]$. The scattering angle was fixed at $165^{\circ}$. The non-RBS cross-sections of ${ }^{4} \mathrm{He}$ ion from $\mathrm{C}$ and $\mathrm{N}[16,17]$ were linked to the RUMP2 program for the RBS data analysis. Transmission electron microscopy (TEM) investigations of the film were performed on a 2010 JEOL microscope at an operating voltage of $160 \mathrm{kV}$. The PzR measurements were carried out using monochromatic light with a spot size of about $1 \mathrm{~mm}$. The sample was mounted on a $0.15-\mathrm{cm}$ thick lead zirconate titanate (PZT) piezoelectric transducer driven by a $200 \mathrm{Vrms}$ sinusoidal wave at $230 \mathrm{~Hz}$. The alternating expansion and contraction of the transducer subjects the sample to an alternating strain. The basic mechanism of the PzR consists of detecting the strain-induced changes of the interband transitions. This technique has been proven to be very useful in the investigation and characterization of hard materials [18]. The principal sample parameters measured are direct band-to-band transition. A detailed description of the PzR apparatus as well as some theoretical background has been reported elsewhere $[18,19]$.

\section{Results and discussion}

A typical scanning electron microscopy (SEM) micrograph of the film deposited by the ECR CVD is shown in Fig. 2. A continuous film was deposited. The film growth rate calculated from film thickness measurement by SEM cross-section view was about $10 \mathrm{~nm} / \mathrm{h}$. The compositions determined by RBS indicate that $\mathrm{Si}, \mathrm{C}$ and $\mathrm{N}$ concentrations were homogeneous throughout the films. Typical $(\mathrm{Si} ; \mathrm{C})$ and $\mathrm{N}$ composition ratios of the film were around 0.75 , close to the stoichiometry of $\mathrm{Si}_{3} \mathrm{~N}_{4}$. The $\mathrm{C}$ and $\mathrm{Fe}$ contents were 4.8 at. $\%$ and 0.3 at.\%, respectively for films deposited at a microwave power of $1.2 \mathrm{~kW}$. The involvement of silicon in chemical reactions leading to film deposition is significant. Deposition without silane addition under otherwise similar

Table 1

Typical deposition conditions for ECR CVD

\begin{tabular}{ll}
\hline Source & $\mathrm{H}_{2}+\mathrm{N}_{2}+\mathrm{CH}_{4}+\mathrm{SiH}_{4}$ \\
{$\left[\mathrm{H}_{2}\right]:\left[\mathrm{N}_{2}\right]:\left[\mathrm{CH}_{4}\right]:\left[\mathrm{SiH}_{4}\right](\mathrm{sccm})$} & $2: 3: 1.25: 0.2$ \\
Total flow rate $(\mathrm{sccm})$ & 6.45 \\
Microwave power $(\mathrm{W})$ & $500-1200$ \\
Total pressure $(\mathrm{mTorr})$ & $3-10$ \\
Substrate temperature $\left({ }^{\circ} \mathrm{C}\right)$ & $500-900$
\end{tabular}




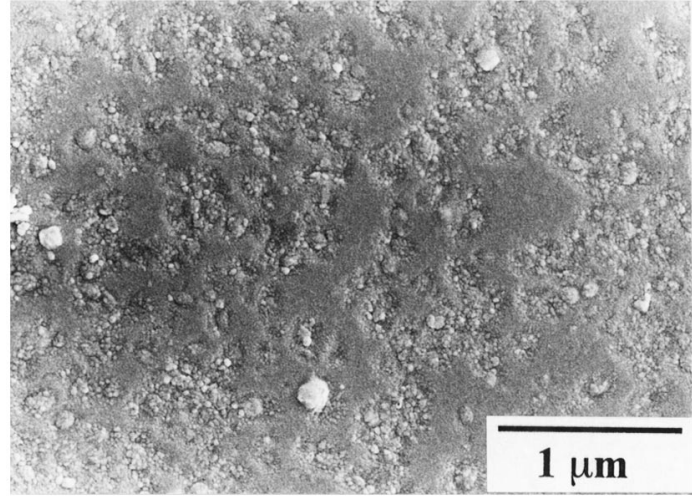

Fig. 2. SEM micrograph of the SiCN film deposited by ECR CVD.

condition did not lead to any crystal growth. Meanwhile, it should be noted that there was 0.3 at.\% Fe contamination within the film, possibly due to high microwave power etching from the ECR chamber wall.

The wide scan XPS spectra of as-deposited films showed the presence of $\mathrm{Si}, \mathrm{C}, \mathrm{N}$ and $\mathrm{O}$ in the material. The oxygen peak at $533 \mathrm{eV}$, however, almost disappeared after sputtering with $\mathrm{Ar}^{+}$ions, indicating that oxygen was present mostly on the surface, while only a trace amount of oxygen was incorporated in the films. Typical high resolution XPS scans of $\mathrm{Si}(2 \mathrm{p}), \mathrm{C}(1 \mathrm{~s})$, and $\mathrm{N}(1 \mathrm{~s})$ peaks are shown in Fig. 3. They reveal that $\mathrm{C}(1 \mathrm{~s})$, and $\mathrm{N}(1 \mathrm{~s})$ peaks comprise more than one Gaussian peak, indicating multiple bonding structures between the constituent atoms $\mathrm{C}$ and $\mathrm{N}$. The $\mathrm{C}(1 \mathrm{~s})$ photoelectron peak comprises two components centered at 284.4 and $285.9 \mathrm{eV}$ respectively, whereas the $\mathrm{N}(1 \mathrm{~s})$ peak also consists of two components centered at 396.8 and $398.6 \mathrm{eV}$ respectively. According to the tentative assignment by Marton et al. [7], they reveal a pure carbon net work, $\mathrm{C}(1 \mathrm{~s})=\mathrm{N}, \mathrm{N}(1 \mathrm{~s})-\mathrm{Si}$ and $\mathrm{N}(1 \mathrm{~s})-\mathrm{C}$, respectively. The $\mathrm{C}-\mathrm{C}$ peak at $284.4 \mathrm{eV}$ disappeared after sputtering with $\mathrm{Ar}^{+}$ ions, indicating that $\mathrm{C}-\mathrm{C}$ bonding was contamination on the surface. Notably, there is no major separate peak that matches the $\mathrm{C}(1 \mathrm{~s})-\mathrm{Si}$ binding energy of $282.8 \mathrm{eV}$, thus suggesting the absence of $\mathrm{Si}-\mathrm{C}$ bonds in the material. The $\mathrm{Si}(2 \mathrm{p})$ photo-electron peaks could not be resolved into more than one peak. The peak centered at $101.2 \mathrm{eV}$ was assigned to $\mathrm{Si}(2 \mathrm{p})-\mathrm{N}$ bonding. Consistent with the results for $\mathrm{C}(1 \mathrm{~s})$ peaks where no major $\mathrm{C}(1 \mathrm{~s})-\mathrm{Si}$ bonding is observed, the $\mathrm{Si}(2 \mathrm{p})$ peaks also show the absence of $\mathrm{Si}(2 \mathrm{p})-\mathrm{C}$ bonding in the vicinity of $100.3 \mathrm{eV}$. Hence, the presence of $\mathrm{Si}-\mathrm{C}$ bonds in the concerned crystals is believed to be negligible.

The XRD spectrum of the SiCN film exhibited many lines. Those diffraction peaks could be roughly indexed to $\alpha-\mathrm{Si}_{3} \mathrm{~N}_{4}$. Transmission electron microscopy was employed to investigate further the microstructure of the $\mathrm{SiCN}$ films. The selected area electron diffraction pattern is shown in Fig. 4a. No apparent diffuse rings were observed. The $d$ spacings calculated from Fig. 4a are listed in Table 2. All $d$ spacings of the film observed from TED pattern, internalcalibrated by the TED pattern of $\mathrm{Si}(100)$ substrate, were
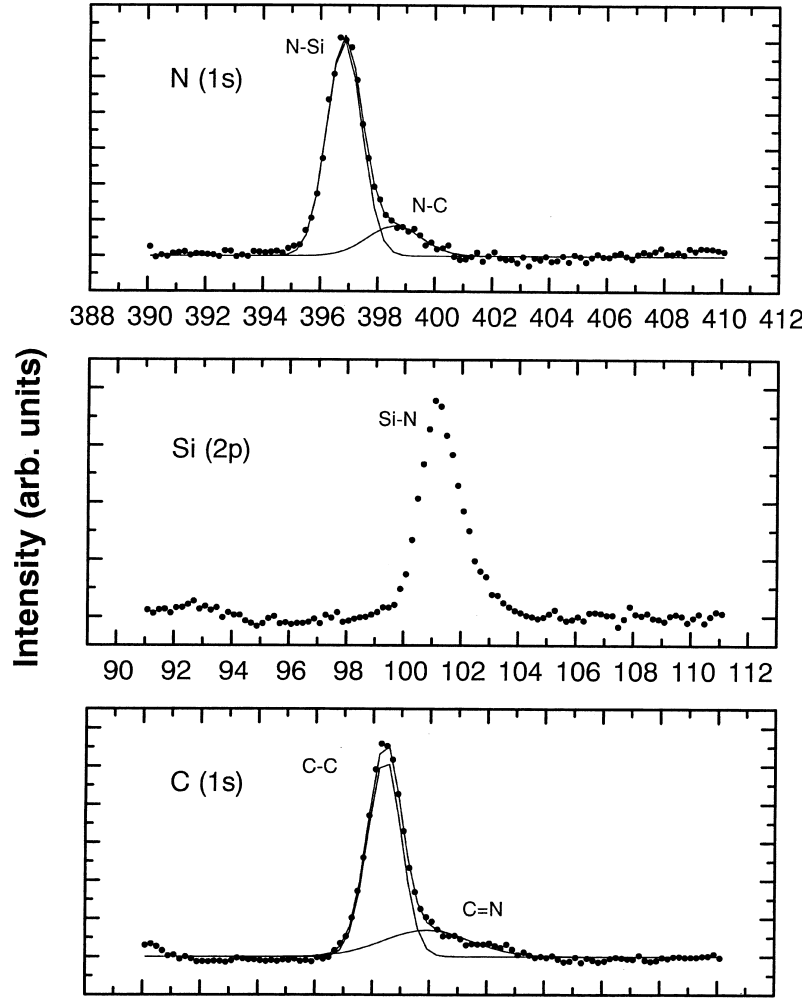

274276278280282284286288290292294296298

Binding Energy (eV)

Fig. 3. Typical XPS spectra of $\mathrm{N}(1 \mathrm{~s}), \mathrm{Si}(2 \mathrm{p})$ and $\mathrm{C}(1 \mathrm{~s})$ in this study.

similar to those of $\alpha-\mathrm{Si}_{3} \mathrm{~N}_{4}$. A relatively high density of crystallites with an average grain size of about $20 \mathrm{~nm}$ was observed from the TEM image of the SiCN film. The grain density of the SiCN film estimated from the TEM image was about $10^{11} \mathrm{~cm}^{-2}$. A high-resolution TEM image of the SiCN film is also shown in Fig. 4b. On a microscopic scale the individual crystals are well crystallized as revealed by

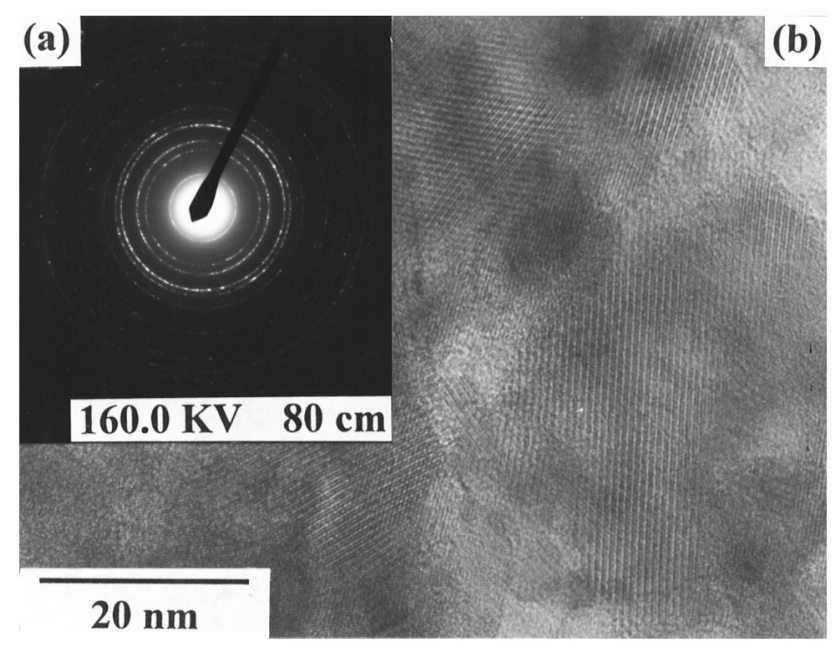

Fig. 4. (a) TED pattern of the SiCN film. (b) HRTEM image of the SiCN film. 
Table 2

Comparison of the $d$-spacings determined from TED with those of $\alpha-\mathrm{Si}_{3} \mathrm{~N}_{4}$

\begin{tabular}{|c|c|c|c|c|c|c|c|c|c|}
\hline \multicolumn{2}{|c|}{ Measured } & \multicolumn{3}{|c|}{$\alpha-\mathrm{Si}_{3} \mathrm{~N}_{4}$} & \multicolumn{2}{|c|}{ Measured } & \multicolumn{3}{|c|}{$\alpha-\mathrm{Si}_{3} \mathrm{~N}_{4}$} \\
\hline$d(\AA)$ & Intensity & $d(\AA)$ & $h k l$ & Intensity & $d(\AA)$ & Intensity & $d(\AA)$ & $h k l$ & Intensity \\
\hline \multirow[t]{2}{*}{6.7} & $\mathrm{~s}$ & 6.69 & 100 & 8 & 1.59 & w & 1.596 & 222 & 35 \\
\hline & & 4.32 & 101 & 50 & & & 1.552 & 312 & 2 \\
\hline 3.88 & s & 3.88 & 110 & 30 & 1.52 & w & 1.542 & 320 & 6 \\
\hline \multirow[t]{3}{*}{3.25} & $\mathrm{~s}$ & 3.37 & 200 & 30 & & & 1.507 & 213 & 8 \\
\hline & & 2.893 & 201 & 85 & & & 1.486 & 321 & 70 \\
\hline & & 2.823 & 002 & 6 & 1.45 & w & 1.437 & 303 & 55 \\
\hline 2.68 & S & 2.599 & 102 & 75 & & & 1.418 & 411 & 60 \\
\hline 2.53 & w & 2.547 & 210 & 100 & & & 1.406 & 004 & 20 \\
\hline \multirow[t]{3}{*}{2.33} & $\mathrm{~m}$ & 2.320 & 211 & 60 & & & 1.376 & 104 & 12 \\
\hline & & 2.283 & 112 & 8 & 1.35 & $\mathrm{~m}$ & 1.351 & 322 & 75 \\
\hline & & 2.244 & 300 & 6 & & & 1.343 & 500 & 2 \\
\hline \multirow[t]{3}{*}{2.19} & w & 2.158 & 202 & 30 & & & 1.321 & 114 & 30 \\
\hline & & & & & & & & 313 & \\
\hline & & 2.083 & 301 & 55 & 1.31 & w & 1.306 & 501 & 16 \\
\hline \multirow[t]{2}{*}{1.92} & w & 1.937 & 220 & 2 & & & 1.299 & 412 & 50 \\
\hline & & 1.884 & 212 & 8 & & & 1.293 & 330 & 30 \\
\hline \multirow[t]{3}{*}{1.84} & w & 1.864 & 310 & 8 & 1.27 & w & 1.269 & 420 & 8 \\
\hline & & 1.806 & 103 & 12 & & & 1.238 & 421 & 30 \\
\hline & & 1.771 & 311 & 25 & 1.22 & vw & 1.229 & 214 & 30 \\
\hline 1.75 & $\mathrm{~m}$ & 1.751 & 302 & 2 & & & 1.213 & 502 & 8 \\
\hline \multirow[t]{2}{*}{1.66} & vw & 1.637 & 203 & 8 & 1.14 & W & & & \\
\hline & & & & & 0.96 & w & & & \\
\hline
\end{tabular}

HRTEM. From the RBS, XPS and TEM results, we suggest the silicon carbon nitride films deposited by ECR CVD possess the same structure as $\alpha-\mathrm{Si}_{3} \mathrm{~N}_{4}$ with around $4.8 \% \mathrm{C}$ substituting for $\mathrm{Si}$.

The direct optical band gap of this new compound was determined by piezo-reflectance (PzR) spectroscopy. Typical PzR spectra of the SiCN film, containing 4.8 at.\% carbon and 0.3 at.\% iron, measured at $300 \mathrm{~K}$ is shown in Fig. 5a. The first derivative of Lorentzian fitting results indicated two band edge transitions around 3.0 and $4.4 \mathrm{eV}$ at $300 \mathrm{~K}$. We suggest that the $\mathrm{SiCN}$ film possesses a direct band gap

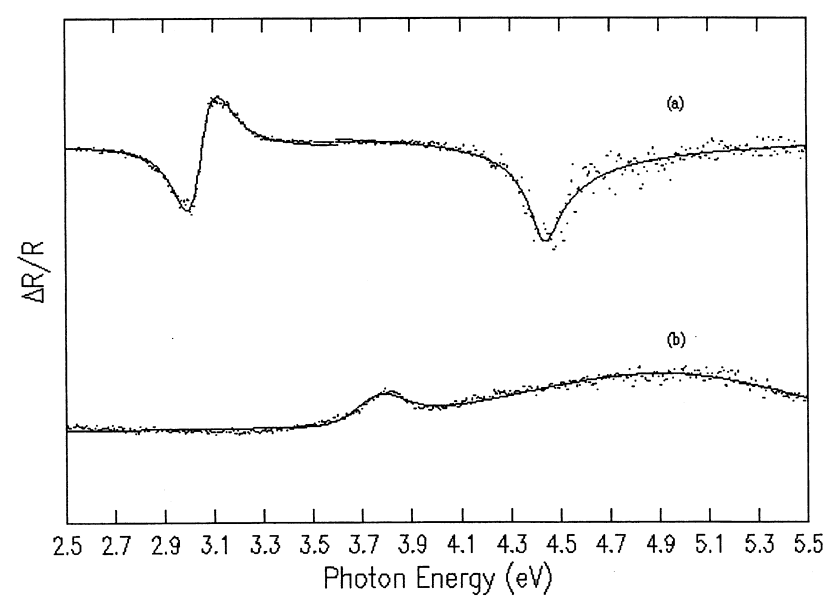

Fig. 5. Piezoreflectance (PzR) spectra of (a) a typical ECR CVD deposited SiCN film, (b) a two-step method deposited SiCN film. of about $4.4 \mathrm{eV}$ that is very close to the $4.7 \mathrm{eV}$ direct band gap of $\mathrm{Si}_{3} \mathrm{~N}_{4}$. The shift in band gap can be attributed to the 4.8 at. \% carbon substitution for $\mathrm{Si}$ in the $\mathrm{Si}_{3} \mathrm{~N}_{4}$ lattice. The $3.0 \mathrm{eV}$ peak observed could be preliminarily attributed to an impurity band resulted from the Fe incorporation within the film. More detailed study is underway to elucidate the semiconductor properties of the SiCN.

In comparison with MWCVD [12-15], the ECR CVD process effectively facilitates $\mathrm{SiCN}$ nucleation. Nucleation densities of the films deposited by ECR CVD were four orders of magnitudes higher than the films deposited by MWCVD. In contrast, the growth rate of the SiCN films deposited by ECR CVD is considerably lower than that by MWCVD. The difference in SiCN growth characteristics by MWCVD and ECR CVD could result from the difference in the gas phase species distribution. Due to its high plasma density, the ECR CVD process under the conditions of this study provides more abundant species facilitating $\mathrm{SiCN}$ nucleation than the MWCVD process. It should also be emphasized that the optoelectronic properties of ECR CVD deposited SiCN films are very different from those of MWCVD deposited ones [15]. For the SiCN crystallite films deposited by MWCVD, the $\mathrm{Si}_{35} \mathrm{C}_{26} \mathrm{~N}_{39}$ film had a direct band gap of about $3.8 \mathrm{eV}$ and an indirect band gap of about $3.2 \mathrm{eV}$, while the $\mathrm{Si}_{38} \mathrm{C}_{5} \mathrm{~N}_{57}$ film deposited by ECR CVD possessed a direct band gap of around $4.4 \mathrm{eV}$. It appeared that the band structure of $\mathrm{SiCN}$ films is dependent on the film composition, while the detailed relationship is yet to be determined. 


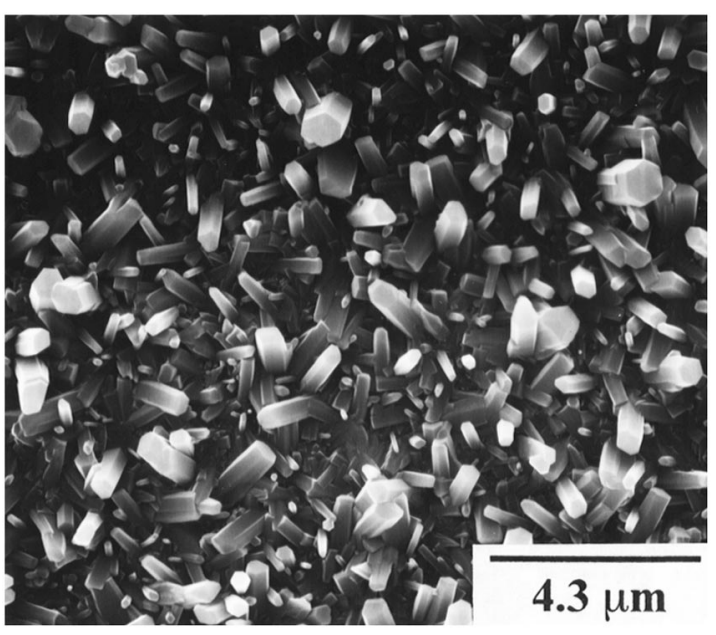

Fig. 6. SEM micrograph of the SiCN film deposited by the two-step method.

To grow SiCN films with larger crystalline size and high nucleation density with reasonable growth rate, a two-step method, combining the ECR CVD and the MWCVD processes were performed. Nanocrystalline $\mathrm{SiCN}$ films were deposited on the silicon substrate by ECR CVD process as buffer layers. On top of the buffer layer, the continuous polycrystalline $\mathrm{SiCN}$ film with the nucleation density of $\sim 10^{9} \mathrm{~cm}^{-2}$ and crystalline size of several microns has been successfully deposited using the MWCVD process with a growth condition as described in Ref. [15]. A scanning electron microscopy (SEM) micrograph of the film deposited by the two-step method is shown in Fig. 6 with the corresponding PzR spectrum in Fig. 5b. It shows that the SiCN film possessed a direct band gap of $3.8 \mathrm{eV}$, which was the same as that of SiCN film in Ref. [15]. The results indicate that the combination of the ECR CVD process (for buffer layer) and the MWCVD process (for growth) makes possible $\mathrm{SiCN}$ film growth at high nucleation density and reasonable growth rate.

\section{Conclusion}

Si-containing crystalline carbon nitride thin films, with high nucleation density up to $10^{11} \mathrm{~cm}^{-2}$, are synthesized on Si substrates using ECR CVD with a source gas mixture containing $\mathrm{CH}_{4}, \mathrm{SiH}_{4}, \mathrm{~N}_{2}$, and $\mathrm{H}_{2}$. RBS studies show a nitrogen content of $57 \%$, a silicon content of $38 \%$, and $4.8 \%$ carbon incorporation. The average grain size estimated from the HRTEM image was about $20 \mathrm{~nm}$. For the SiCN film with 4.8 at.\% carbon content, all $d$-spacings of the film observed from TED pattern were similar to those of $\alpha$ $\mathrm{Si}_{3} \mathrm{~N}_{4}$. High resolution XPS scans showed that the presence of $\mathrm{Si}-\mathrm{C}$ bonds within the film was negligible. From the RBS, XPS and the TEM results, we suggest the silicon carbon nitride film possessed the same structure as $\alpha$ $\mathrm{Si}_{3} \mathrm{~N}_{4}$ with around 4.8 at.\% $\mathrm{C}$ substituting for $\mathrm{Si}$. It is also demonstrated that this new compound has a direct band gap of about $4.4 \mathrm{eV}$ and an impurity band gap at around $3.0 \mathrm{eV}$. Thus the ternary SiCN compound reported here constitutes an important addition to wide band gap materials with gap energies within the blue spectral region. Furthermore, the nanocrystalline $\mathrm{SiCN}$ films deposited by the ECR CVD process were excellent buffer layers for the $\mathrm{SiCN}$ film growth with reasonable growth rate, larger crystallite size, and high nucleation density by the MWCVD process.

\section{Acknowledgements}

Financial support for this project from National Science Council, Taiwan, under contract no. NSC-88-2113-M-001021 and NSC-88-2112-M-002-022 is gratefully acknowledged. One of the authors, Dr J.J. Wu, acknowledges the postdoctoral fellowship awarded by the National Science Council.

\section{References}

[1] A.Y. Liu, M.L. Cohen, Science 245 (1989) 841.

[2] Z.J. Zhang, S. Fan, J. Huang, C.M. Lieber, Appl. Phys. Lett. 68 (1996) 2639.

[3] D. Li, Y.W. Chung, M.S. Wong, W.D. Sproul, J. Appl. Phys. 74 (1993) 219

[4] Z.M. Ren, Y.C. Du, Z.F. Ying, Y.X. Qiu, X.X. Xiong, J.D. Wu, F.M. Li, Appl. Phys. Lett. 65 (1994) 1361.

[5] C. Niu, Y.Z. Lu, C.M. Lieber, Science 261 (1993) 334.

[6] S. Kumar, T.L. Tansley, Solid State Commun. 88 (1993) 803.

[7] D. Marton, K.J. Boyd, A.H. Al-Bayati, S.S. Todorov, J.W. Rabalais, Phys. Rev. Lett. 73 (1994) 118.

[8] K.M. Yu, M.L. Cohen, E.E. Haller, W.L. Hansen, A.Y. Liu, I.C. Wu, Phys. Rev. B 49 (1994) 5034.

[9] J.P. Riviere, D. Texier, J. Delafond, M. Jaouen, E.L. Mathe, J. Chaumond, Mater. Lett. 22 (1995) 115.

[10] C-Y. Hsu, F. C-N, Hong, Jpn. J. Appl. Phys. Lett. 37 (1998) L675.

[11] C-Y. Hsu, F. C-N, Hong, Jpn. J. Appl. Phys. Lett. 37 (1998) L1058.

[12] D.M. Bhusari, C.K. Chen, K.H. Chen, T.J. Chuang, L.C. Chen, M.C. Lin, J. Mater. Res. 12 (1997) 322.

[13] L.C. Chen, C.Y. Yang, D.M. Bhusari, K.H. Chen, M.C. Lin, J.C. Lin, T.J. Chuang, Diamond Rel. Mater. 5 (1996) 514.

[14] L.C. Chen, D.M. Bhusari, C.Y. Yang, K.H. Chen, T.J. Chuang, M.C. Lin, C.K. Chen, Y.F. Huang, Thin Solid Films 303 (1997) 66.

[15] L.C. Chen, C.K. Chen, S.L. Wei, D.M. Bhusari, K.H. Chen, Y.F. Chen, Y.C. Jong, Y. Huang, Appl. Phys. Lett. 72 (1998) 2463.

[16] Y. Feng, Z. Zhou, Y. Zhou, G. Zhao, Nucl. Instrum. Methods B 86 (1994) 225

[17] Y. Feng, Z. Zhou, G. Zhao, F. Yang, Nucl. Instrum. Methods B 94 (1994) 11.

[18] P.Y. Yu, M. Cardona, Fundamentals of Semiconductors, Springer, Berlin, 1996 p. 307.

[19] D.Y. Lin, C.F. Li, Y.S. Huang, Y.C. Jong, Y.F. Chen, L.C. Chen, C.K. Chen, K.H. Chen, D.M. Bhusari, Phys. Rev. B 56 (1997) 6498. 